\title{
Anos depois, o Movimento Bixigão
}

\author{
Years later, the "Movimento Bixigão" \\ Maíra Gerstner \\ Maria Lúcia de Souza Barros Pupo
}

Maíra Gerstner

Psicoterapeuta e doutoranda em Artes Cênicas pela Escola de

Comunicações e Artes da Universidade de São Paulo.

Maria Lúcia de Souza Barros Pupo

Docente titular no Departamento de Artes Cênicas na

Escola de Comunicações e Artes da Universidade de São Paulo.

É pesquisadora do CNPq.

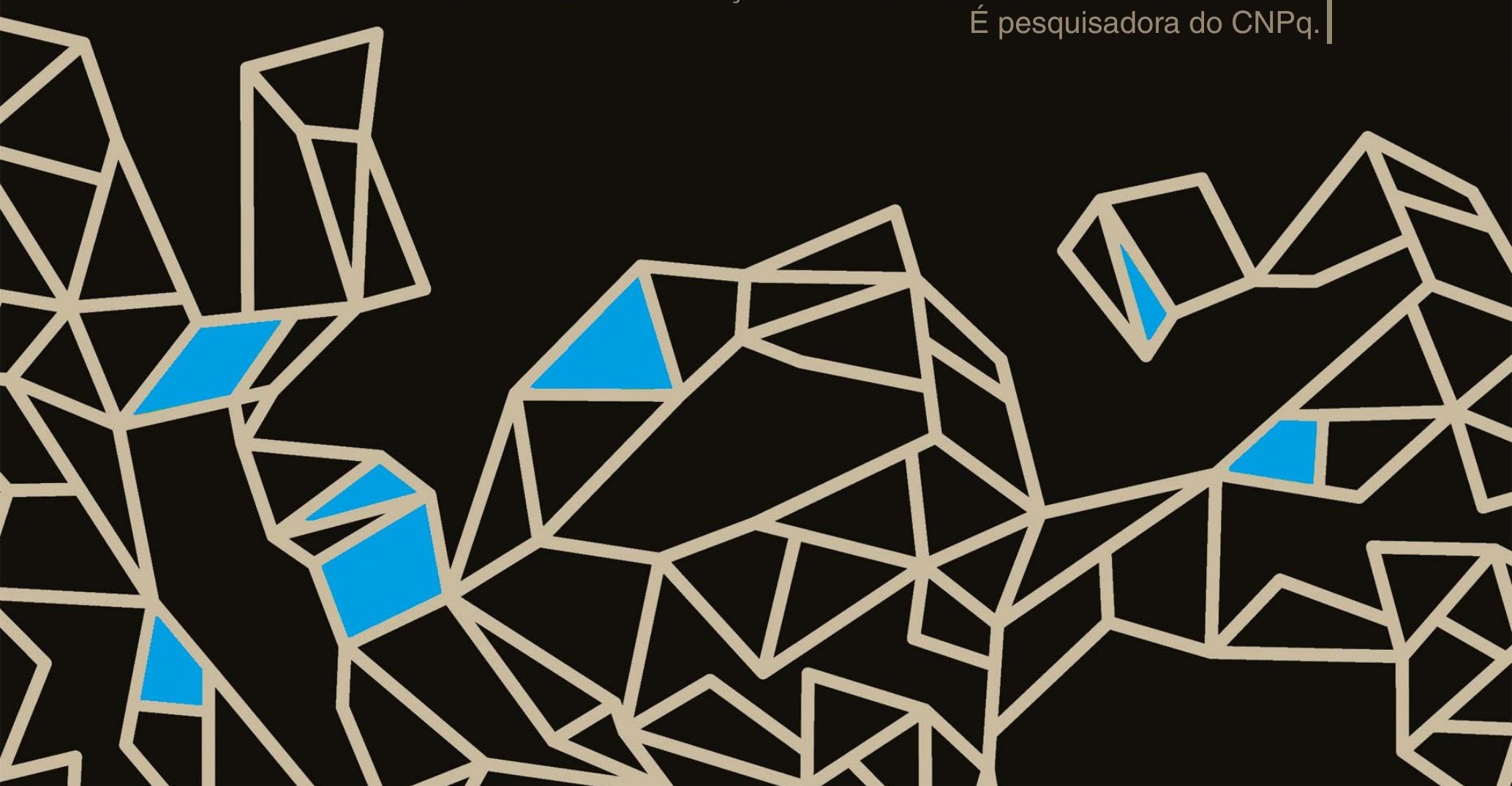




\section{Resumo}

O texto é resultado do processo de pesquisa de um ano e meio desenvolvido em 2007 e 2008 no Núcleo de Voz do "Movimento Bixigão". Ressalta aspectos centrais da investigação realizada, como o surgimento do Movimento, o trabalho do Núcleo realizado naquele contexto e o legado da experiência em relação à trajetória do Teatro Oficina.

Palavras-chave: Movimento Bixigão - Núcleo de Voz, Teatro Oficina, Experiência e palavra, Texto e jogo.

\section{Abstract}

This text results of a year and a half research process developed in 2007 and 2008 at the Voice Center of the "Movimento Bixigão". It highlights central aspects of the investigation, such as the emergence of the Movement, the work of the Center and the legacy of the experience in relation to the trajectory of Teatro Oficina.

Keywords: Movimento Bixigão - Voice Center, Teatro Oficina, Experience and word, Text and play.

Quase 13 anos depois, voltamos a dirigir nosso olhar para a aventura que foi o Movimento Bixigão. O "nós", aqui subentendido, resulta da parceria entre Maíra Gerstner, autora de um trabalho de conclusão de curso de Licenciatura em Artes Cênicas na Escola de Comunicações e Artes da Universidade de São Paulo (ECA-USP) em 2008 sobre aquela bela iniciativa do Teatro Oficina, e Maria Lúcia de Souza Barros Pupo, docente responsável pela orientação da pesquisa que nele desembocou.

Nosso intuito, assim, será trazer à tona alguns aspectos daquela experiência, dado que o projeto está diretamente relacionado com esse acontecimento singular na história do teatro no Brasil, que é o Teatro Oficina.

O que valeria a pena retomar de uma experiência passada tendo em vista a calamidade que estamos vivendo coletivamente? Sobretudo em um ano em que "a presença", tão cara ao teatro, se deu de maneira remota? É importante frisar este momento para que se dimensione o lugar de onde 
parte a escrita. Com isso, as tramas entre passado, presente e futuro vão sendo tecidas pelos misteriosos fios do tempo. $\mathrm{E}$ a presença se mostra nas memórias dos corpos que viveram tudo aquilo que só a potência do encontro pode proporcionar.

A experiência com a palavra do Movimento Bixigão, título do trabalho de conclusão de curso em licenciatura em Artes Cênicas de Maíra Gerstner, foi resultante de um processo de um ano e meio (2007-2008) à frente do Núcleo de Voz do Movimento Bixigão, em parceria com a fonoaudióloga Thaisa Palma. Maíra e Thaisa haviam sido alunas de Lúcia Helena Gayotto, ex-atriz e preparadora vocal do Teatro Oficina - Thaisa no curso de fonoaudiologia da Pontifícia Universidade Católica de São Paulo (PUC-SP) e Maíra no curso de Artes Cênicas da USP.

Tendo em vista recuperar tal processo à luz dessa distância temporal, pensamos que seria importante ressaltar aspectos centrais da investigação realizada, tais como o surgimento do Movimento Bixigão, o trabalho do Núcleo de Voz que se deu naquele contexto e, por fim, o legado desta experiência em relação à trajetória do Teatro Oficina.

\section{"Eles são os verdadeiros sertanejos"}

Os Sertões foi um marco na história do teatro brasileiro do início dos anos 2000. Difícil dizer se foi ou foram, uma vez que a peça era dividida em cinco partes, quase todas tradicionalmente longas, como é peculiar ao Teatro Oficina. O coro do Movimento Bixigão, sem dúvida, fortaleceu esse marco. Assistir àqueles jovens formando um coletivo vibrante em cena era, sem dúvida, uma experiência potente. Eram eles os verdadeiros sertanejos, conforme pontuava Sylvia Prado, coordenadora do projeto que nos ocupa aqui. E, para os envolvidos no campo da pedagogia teatral, o interesse era duplo: qual teria sido o caminho para a chegada deles ali? Como se davam os ensaios? O que era, enfim, o Bixigão?

O Movimento Bixigão nasce em 2002, fruto de uma parceria realizada entre alguns artistas da Cia Uzyna Uzona e Pedro Epifânio, líder comunitário do bairro. $\mathrm{O}$ nome veio como uma brincadeira, um trocadilho proposto pelo ator Marcelo Drummond com o Piscinão de Ramos, no Rio de Janeiro. 
Passaram a trabalhar com crianças de uma ocupação na rua da Abolição, e o desdobramento do trabalho (que tinha como projeto inicial encenar Horácios e Curiácios de Bertolt Brecht) levou à participação deste núcleo de jovens do bairro do Bixiga na montagem de Os Sertões.

Em 2007, o Bixigão assume uma casa no bairro do Bixiga, mais precisamente na rua Maria José, 140, e é transformado em Ponto de Cultura, oferecendo oficinas de domingo a domingo para o público jovem. Além das aulas de teatro, que eram compostas por tea-to ${ }^{1}$, dramaturgia, figurino, estudo de texto, voz e corpo, também eram ministradas aulas de música, circo, jardinagem, internet, vídeo e produção.

$\mathrm{Na}$ ocasião da estruturação das oficinas do Bixigão, já como Ponto de Cultura, Sylvia Prado, como dissemos coordenadora do projeto e também atriz do Oficina, convidou Lúcia Gayotto para assumir as aulas do Núcleo de Voz. Sem condições de aceitar, ela indicou a dupla de ex-alunas que conduziriam a prática com sua orientação. É nesse contexto que se deu o trabalho de Maíra e Thaisa. Neste momento, o grupo de professores era composto por artistas que faziam parte do Teatro Oficina e por outros não vinculados a ele (Maíra e Thaisa faziam parte deste segundo grupo). Pessoas como Camila Motta, Pascoal da Conceição, Letícia Coura, Lucas Weglinski, Flavia Lobo, Adriana Macul, Ferdinando Martins e Yoda fizeram parte do corpo docente do projeto.

Em 2008, não eram mais só os jovens que tinham feito parte de Os Sertões que participavam das oficinas. Outros jovens interessados em aulas ligadas ao Teatro Oficina passaram a participar também. Falava-se, naquele momento, que o Bixigão começava a ter algo particular em relação ao seu surgimento. Como se estivesse buscando para si sua singularidade. Essa dimensão esteve presente durante toda a jornada do Núcleo de Voz no Movimento Bixigão. Nesse sentido, vale a pena pensar que o projeto artístico-pedagógico que se dava no Bixigão teve caráter absolutamente experimental. Era fruto de uma experiência que seu deu em uma obra teatral da grandeza de Os Sertões, contando também com outros artistas que não faziam parte do Oficina.

1 Prática desenvolvida pelo Teatro Oficina desde os anos 1970, oriunda do encontro do grupo com o Living Theatre. $O$ trabalho foi sistematizado e prima basicamente pela ideia de "acontecimento" teatral. No Bixigão, a aula é conduzida pela atriz Camila Motta, que tem investido principalmente na relação com o trabalho de coro. 


\section{"Eu fui mudado pelos Sertões"}

"Eu sou um catarinense descendente de alemães com índios carijós e eu entendi isso depois que vi Os Sertões. Eu fui mudado pelos Sertões". Essa foi uma fala ${ }^{2}$ de Rafael, um dos participantes do Núcleo de Voz no ano de 2008. Assim como ele, muitos se perguntaram sobre o que é ser brasileiro diante daquela obra. E foi essa experiência tão forte que fez Rafael buscar as aulas oferecidas no Bixigão naquele momento.

Rafael fazia parte desse novo grupo que se formava: poucos ex-integrantes dos Sertões e outros participantes novos, muitos entre os 16 e 30 anos, que surgiam interessados nas aulas pelos motivos os mais diversos. Tínhamos, já no final do trabalho do Núcleo de Voz, um coletivo de pessoas que estavam no Bixigão desde o seu início e outros que haviam chegado há seis meses.

Por isso, um dos aspectos que deflagraram a singularidade do Bixigão no período em que o Núcleo de Voz foi atuante, entre os anos de 2007 e 2008, foi a importância dada à dimensão formativa dos jovens. Ou seja, a aprendizagem da linguagem teatral não deveria acontecer tão somente no fazer dos espetáculos, mas também e ainda mais no contexto das aulas. Importante ressaltar aqui também o que seria essa formação. Mais do que uma formação em teatro, pensava-se em uma formação para a vida. Ou seja, não havia o objetivo de criar uma escola de formação de atores, muito pelo contrário. Tinha-se, sim, como norte, que aquela experiência seria um laboratório para a futura criação da Universidade Livre de Estádio, a Universidade Antropofágica Brasileira, projeto de Zé Celso que engloba diversos matizes, passando sobretudo pela luta do Teatro Oficina em manter seu espaço (na conhecida disputa com o Grupo Silvio Santos) e toda a ativação cultural do bairro do Bixiga.

O final do ano de 2007 foi marcado pela leitura pública ${ }^{3}$ do texto Cypriano e Chantalan, de Luís Antônio Martinez Corrêa, irmão de Zé Celso. Com direção

2 Em 2008, Maíra Gerstner realizou o documentário Três instantes na criação, no qual entrevistou integrantes dos três coletivos teatrais com os quais estava envolvida naquele momento: o Movimento Bixigão, um grupo de atores formandos na Escola de Artes Dramáticas (EAD) dirigidos por Christiane Paoli Quito, e o pH2: estado de teatro formado por alunos do curso de Artes Cênicas da ECA. A fala de Rafael ocorreu no contexto desse filme.

3 A leitura ocorreu no dia 23 de dezembro de 2007, dia do "renascimento" de Luís Antônio Martinez Corrêa. Todo ano, o Oficina realiza uma ação em prol da memória do irmão de Zé Celso, assassinado em seu apartamento no Rio de Janeiro por homofobia nos anos 1987. 
do próprio Zé, a leitura foi composta por atores do Oficina e alguns membros do Bixigão. Tendo sido uma experiência rápida de criação para uma apresentação, gerou intensa discussão sobre qual seria o foco do trabalho pedagógico do Bixigão em 2008. Uma série de reuniões foram então realizadas a fim de pensar um projeto para o ano que se seguiria.

Assim, uma das decisões tomadas foi a de que, naquele ano de 2008, todas as oficinas teriam em comum o universo das referências presentes no texto Cypriano e Chantalan. O mais interessante, aqui, é que o autor dedica seu texto a diversas pessoas, que nomina como os "sensacionais", dentre os quais estão Arrabal, Cortázar, Shakespeare, Artaud, Dercy Gonçalves e Lily Brik. Todos eles ocupam as três primeiras páginas do texto e seriam como nosso alimento naquele instante.

Em maio de 2008, foi realizada a montagem de Cypriano e Chantalan com a participação dos integrantes do Movimento Bixigão e, dessa vez, com a direção de Marcelo Drummond. O processo foi pensado muito mais no âmbito do estudo do que no da apresentação de um espetáculo. No entanto, tendo em vista que os jovens trabalhassem pontos específicos daquela montagem, algumas oficinas do Bixigão - principalmente as de música e vídeo foram interrompidas.

No Núcleo de Voz já tínhamos iniciado um processo com poemas de Vladimir Maiakóvski no qual pretendíamos prosseguir. Além disso, o fato de as professoras não estarem participando da montagem de Cypriano e Chantalan não lhes permitia trabalhar questões de atuação da peça, pois não estávamos inteiradas dos encaminhamentos propostos pela direção. Chegamos, contudo, a realizar um pequeno workshop relativo a uma cena, com dois atores, mas se tratou de uma situação isolada.

\section{"Mas, Maíra, pra mim é difícil falar e andar"}

A fala de Isabela, uma das alunas do Bixigão, que também tinha feito parte de Os Sertões, foi interessante para trazer à tona uma dimensão tida como simples, afinal fazemos isso na vida comum, andamos e falamos - assim como fazemos isso em cena. Mas onde estaria sua dificuldade ou, ainda, o que a dificuldade ali exposta deflagraria no nosso próprio processo no Núcleo de Voz? 
Iniciava-se assim a experiência com a palavra a partir do diálogo entre corpo e voz. Este trabalho foi norteado principalmente pela noção de jogo, uma vez que a palavra esteve presente sempre em forma de fragmentos textuais ou nas consignas de exercícios que evidenciavam a abordagem seguinte. De todo modo, só a partir da noção de jogo é que foi possível conceber a palavra em sua concretude, na sua dimensão de matéria.

Neste trabalho foram fundamentais as noções de teatralidade e performatividade de Josette Féral, bem como o trabalho de Paul Zumthor em seu Performance, recepção, leitura, que forneceu preciosas ideias para pensar a "exploração da palavra". Paul Zumthor atenta para o fato de que a própria ideia de palavra que concebemos também é produto de um conceito:

\begin{abstract}
Muitas línguas africanas conservaram uma fraseologia mostrando que as culturas correspondentes não elaboraram o conceito geral de palavra: uma multiplicidade de atos vocais assume funções sociais distintas umas das outras. Os ewé, população do sul da Nigéria, que possui antigas e ricas tradições, distinguem, segundo as regiões, cinco, seis, ou nove funções diferentes, em limites bem traçados, daquilo que nós reunimos sob o nome de palavra. (ZUMTHOR, 2000, p. 14)
\end{abstract}

Alguns pontos se tornaram fundamentais no tocante à exploração da palavra: tomá-la como matéria, a partir de sua concretude; a relação corpo/som/ espacialidade, tendo em vista as dinâmicas que propunham o engajamento do corpo na sua ocupação do espaço e na produção de sonoridades; a tríade escuta/emissão/afetação, advinda da combinação de alguns princípios como a noção de imagem da palavra (trabalhada por Cristiane Paoli Quito) e as práticas com texto e jogo desenvolvidas por Maria Lúcia Pupo.

As aulas em geral começavam com uma prática de aquecimento corporal e vocal para, em seguida, se encaminhar algum exercício em que se focalizasse a palavra, mas em uma palavra que não estivesse presente textualmente. Antes de abordarmos o material textual (por exemplo, os poemas de Maiakóvski), a palavra se mostrava de outras formas. Trabalhamos princípios de prontidão cênica com bastões, bolinhas de tênis ou, ainda, nas dinâmicas do platô, diagonais pelo espaço e depois, introduzíamos uma instrução indicando alguma questão relacionada à palavra. Por exemplo, "ao jogar o bastão 
para o outro, diga o nome de quem você chama"; "ao caminhar até o outro, estabeleça o contato ocular e o presenteie com uma palavra".

Assim as práticas podiam acontecer tanto no âmbito do aquecimento vocal, como na introdução com a palavra, quanto no trabalho com o texto. O exercício linhas, por exemplo, acontecia nas diagonais do espaço e, também, nas linhas que se construíam entre os participantes espalhados pelo espaço. De todo modo, o objetivo do trabalho era estabelecer uma sincronia entre a caminhada e a emissão do som ou da palavra.

Outro princípio que se tornou fundamental na exploração com a palavra foi a tríade escuta/emissão/afetação, que norteou boa parte dos exercícios com os fragmentos textuais e que têm caráter eminentemente coletivo. Eis aqui as definições traçadas acerca da tríade:

- Escuta - Abrange a percepção sobre si e sobre o outro, criando um jogo no qual possa existir a abertura de um canal daquilo que se recebe;

- Emissão - Processo no qual o som é expresso. Na pesquisa em questão, a emissão se dava em dois momentos distintos: primeiramente para si, ao fazer contato inicial com o texto, trazendo as imagens que ele suscita a partir do que é dito. Depois, a emissão passava a ser o resultado dos diversos processos de afetação do jogo;

- Afetação - Transformação que ocorre no como a palavra é dita a partir de forças externas (no caso, a fala do outro) que atravessavam uma percepção inicial, promovendo algum tipo de mudança na fala.

Para pensar a noção de afetação no âmbito do jogo, é possível estabelecer novamente um diálogo com Zumthor, principalmente quando o autor sugere que as palavras têm espessura:

Ela (a retórica da Antiguidade) ensinava, à sua maneira, que para ir ao sentido de um discurso, sentido cuja intenção suponho naquele que me fala, era preciso atravessar as palavras; mas que as palavras resistem; elas têm espessura, sua existência densa exige, para que elas sejam compreendidas, uma intervenção corporal, sob a forma de uma operação vocal: seja aquela da voz percebida, pronunciada e ouvida ou de uma voz inaudível, de uma articulação interiorizada. (Ibid., p. 89) 
Assim, entre as práticas e os exercícios cujo foco era o trabalho sobre a escuta/emissão/afetação, podemos destacar, por exemplo:

1. Eram formadas duas rodas, uma dentro da outra. Isso possibilitava o encontro frontal entre as duplas. Desse modo, uma das rodas girava, mudando os pares. Cada um devia lançar um fragmento de texto ao parceiro. $\mathrm{O}$ que recebia devia perceber como a palavra do outro o afetava e proporcionava outro estado para o que seria dito em seguida.

2. Todos pelo espaço. $O$ foco era a palavra. A partir de um primeiro contato ocular, devia-se lançar um pequeno fragmento de texto ao outro. O outro recebia, havia o momento de recepção e, em seguida, era lançado outro fragmento a outro parceiro, a partir desse estado de mobilização.

3. Metade do grupo estava sentado no chão, de olhos fechados. A outra metade, em pé, lançava ao pé do ouvido fragmentos de texto aos parceiros. Esse trabalho é interessante não só em relação à escuta/ emissão/afetação, mas também como fomentador da construção de imagens advindas do texto.

Um dos primeiros materiais textuais que trabalhamos foi o "Prólogo dos sete pares impuros", trecho de Mistério bufo, de Vladimir Maiakovski. Foi pedido que eles escrevessem as imagens que o texto havia suscitado, ou seja, aquilo foi visto na imagem da palavra ${ }^{4}$. Fomos percebendo que, quando convidados a escrever sobre a experiência, os jovens se sentiam menos intimidados do que ao expor impressões em um primeiro momento ao grupo. Por isso, a escrita foi ganhando grande importância no decorrer do processo e, assim, também fomos descobrindo, aos poucos, formas de tornar aquelas impressões também passíveis de compartilhamento.

4 A noção de imagem da palavra, trabalhada por Cristiane Paoli Quito (para a qual Maíra Gerstner fazia assistência de direção em 2008 na montagem Ato sem palavras I, de Samuel Beckett, na EAD), consiste em uma série de procedimentos de estímulos sensoriais diversos, com o objetivo de trazer à tona o que a palavra suscita como imagem. Ou seja, mais do que compreender o que a palavra já suscita a priori, é abrir espaço para que a palavra possa se revelar em imagem sem tomá-la como coisa dada. Assim, é possível se surpreender com as diversas imagens improváveis que podem vir a surgir. 


\section{“Todo mundo vai morrer: eu vou, você vai...."}

A segunda etapa da experiência com a palavra no Movimento Bixigão se deu a partir de vivências ligadas à cartografia urbana e explorações sensório-poéticas das ruas do bairro do Bixiga. Percepções que se deram na escuta e, depois, se transformaram também em textos, sendo posteriormente articulados aos demais trechos que já vinham sendo trabalhados. "Todo mundo vai morrer: eu vou, você vai" apareceu como uma fala de um morador do bairro do Bixiga durante esse processo e, posteriormente, foi incorporada como texto.

O grupo explorou o bairro ora de olhos vendados, em dupla, buscando dar atenção aos sons da rua, ora com gravadores, entrevistando moradores do bairro. É importante ressaltar também que essa ida à rua dialogava com propostas de ocupação do espaço urbano que vinham sendo trazidas por outros professores, sobretudo os diretamente ligados ao Teatro Oficina, como Camila Motta.

Entre os dias 7 e 13 de dezembro de 2008, houve uma Semana Cultural na sede do Movimento Bixigão. Apresentações, exposições, laboratórios e aulas abertas foram realizados com o objetivo de finalizar os trabalhos daquele ano. A programação contou com: exposição fruto da oficina de tecelagem, com Lala Martinez Corrêa e Flávia Lobo; laboratório de áudio, com Leo e Yoda; apresentação da peça $A$ entrevista, com direção de Pascoal da Conceição; aula aberta de corpo, com Adriana Macul; apresentação de circo, com Daniel Carrão; performance dionisíaca, com direção de Ferdinando Martins e Rafael Ghiraldello; aula aberta de voz, com Maíra Gerstner e Thaisa Palma; aula de música, com Letícia Coura e Vítor da Trindade; exibição de vídeos e figurinos, com coodenação de Lucas Weglinski, Elaine Cesar e Flavia Lobo; e aula de te-ato, com Camila Motta.

Pensar hoje nessas aberturas de processo nos faz chegar diante do seguinte dilema: como tornar um exercício teatral interessante aos olhos de quem vê? Como é possível esgarçar os limites entre teatralidade e performatividade, como nos aponta Josette Féral, no campo da pedagogia teatral? Um exercício é só um exercício? Precisamos sempre da noção de "obra" para que a experiência de recepção possa acontecer? Todas essas perguntas fizeram parte da jornada deste trabalho e continuam ainda presentes na ótica destas que vos escrevem. 
O conceito de teatralidade desenvolvido por Josette Féral nos ajuda a compreender a experiência no sentido da dimensão performativa do processo. Para a autora, uma das condições principais para que exista teatralidade é a constituição de um "espaço outro", caso contrário, não haveria a possibilidade de existir teatro, porque o outro estaria sempre em meu espaço imediato, cotidiano. E chama atenção para o ato performativo de quem faz e de quem vê:

A teatralidade é um fazer, um suceder que constrói um objeto antes de consagrá-lo como tal. Esta construção é o resultado de uma dupla polaridade que pode partir da cena e do ator quanto só do espectador. (FÉRAL, 2004, p. 92)

Féral também chama atenção para a noção de performatividade presente na cena contemporânea, muito ligada à ideia de realização de uma ação que não necessita se apresentar como verdadeira ou falsa, deixando de lado o conceito de verossimilhança e tornando os signos cênicos mais fluídos. Segundo ela:

No teatro performativo, o ator é convocado a "fazer", a "estar presente", a correr os riscos e a mostrar o que faz, e deste modo afirma a performatividade do processo. A atenção do espectador se dá sobre a execução de um gesto, sobre a criação de uma forma, a dissolução dos signos e a reconstrução permanente. Uma estética da presença por assim dizer. (Id., 2008, p. 17)

Ao final, a autora apresenta a seguinte questão "Estaria este teatro afastado, do mesmo modo, da teatralidade?" (Ibid., p. 17). Féral confronta os conceitos de teatralidade e performatividade e, assim, evidencia um limite entre ambos, que nos auxilia na compreensão de uma prática que pensa a noção de experiência dentro desse terreno limítrofe. E então, onde começa a cena? É possível conceber a quebra da dicotomia existente entre processo e produto, uma vez que o processo em si pode ser considerado cena, principalmente se pensarmos na estética da presença?

Na medida em que a prática foi se complexificando, a preocupação de tornar um exercício interessante aos olhos de quem vê foi se diluindo aos poucos, mas nunca desapareceu por completo. Apenas foi se desdobrando 
em aspectos que foram se mostrando mais relevantes para o avanço do processo. Porém, em algumas premissas do trabalho, é possível verificar o relevo que tomou tal preocupação.

Tanto no final de semana de encerramento das atividades como no dia de apresentação do trabalho de conclusão de curso de Maíra, na ECA-USP, o grupo foi convidado a compor um roteiro de ações que seria apresentado. O roteiro tinha por início os exercícios de aquecimento de corpo e voz, a exploração com a palavra a partir dos textos, o percurso pela rua e, também, um fechamento trazendo as impressões de cada um sobre o vivido.

E aqui chegamos, talvez, em uma dobra. Ao pensar que a apresentação de uma "cena", fruto de uma exploração em um exercício como caminhar pelo espaço, olhar uns nos olhos dos outros etc., pudesse ter um caráter mais intimista, podemos nos perguntar se isso traria outra noção de "cena" para aquele território fruto da poética do Teatro Oficina, conhecido por seu trabalho de multidão.

Naquele momento, era possível vislumbrar uma contradição entre a relevância da continuidade do processo de formação dos participantes por um lado e, por outro, as demandas oriundas do próprio Oficina no sentido de que aqueles jovens fossem incorporados aos acontecimentos cênicos em preparação pelos artistas. Tratava-se de uma escolha que hoje talvez ganhasse outros contornos. Na medida em que o caráter performativo e lúdico das práticas desenvolvidas pelo Bixigão fosse compreendido não como preparação para, mas como uma ação artística em si mesma, a pretensa dicotomia entre processo e produto poderia ser superada. Os exemplos aqui descritos fazem emergir o potencial das experiências realizadas então pelos participantes enquanto formas cênicas a serem eventualmente compartilhadas com espectadores.

Com isso, vale a pena reconhecer que no Bixigão era possível coexistirem diferentes pensamentos artísticos entre os professores, o que era de notável riqueza, pois assim os jovens vivenciavam diversas perspectivas do que chamamos de arte e de cultura. Isso só era possível, de certo modo, pelo caráter experimental do projeto, pela ausência de um projeto pedagógico no sentido estrito e, mais ainda, por certa anarquia inerente aos pressupostos de criação do Oficina, sempre muito marcados por elementos da contracultura e da contestação dos valores morais de nossa época. 


\section{"Porque o Bixiga não tem que só ser o Bixiga, entende?"}

Fernando, um dos integrantes do Movimento Bixigão, certa vez lançou esse questionamento no contexto do trabalho, no momento das cartografias urbanas e na saída para a rua. Como participante do grupo que não tinha feito parte de Os Sertões, ele evidenciava com essa fala muitas camadas de complexidade presentes em nosso trabalho.

A primeira dessas camadas evidenciava as diferentes estéticas do grupo docente daquele momento, formado por pessoas ligadas ao Teatro Oficina e outras sem ligação direta com o grupo. Outro nível de complexidade advinha do fato de que a criação da Universidade Livre de Estádio ou Universidade Antropofágica Brasileira era um norte para o trabalho. Mesmo que nem todos tivessem clareza do que isso viria a ser exatamente, podemos pensar que ali existia algo que pulsava em termos de desejo por outra cidade, outra educação e modos distintos de se relacionar com o outro.

O projeto da Universidade Antropofágica Brasileira (ou Universidade Livre de Estádio) sempre é muito citado por Zé Celso nos espetáculos do Oficina. Ele engloba toda uma área que envolve o terreno do teatro (que teve seu edifício projetado pelas mãos de Lina Bo Bardi e é tombado pelo Conselho de Defesa do Patrimônio Estadual - Condeephat), além de uma série de articulações com outros espaços do bairro. $O$ projeto prevê diversas ações culturais e educativas, como também a construção de uma área verde no local, incluindo o Minhocão, proposta hoje encabeçada pelo Movimento do Parque do Bixiga.

O Bixigão, para aqueles jovens, era mais que o Bixigão. Era mais do que estar em cena. Era estar junto, fazer parte de um grupo que trazia uma noção de pertencimento, tão importante nesse nosso momento de vida. Era a possibilidade de aprender coisas novas sobre o mundo. Seja sobre quem foi Maiakóvski ou Stanislávski, mas também como é fazer pão, trabalhar com software livre. Sonhar junto. Enfim, experimentar o que só a experiência de grupo em teatro nos ensina. $E$ quem experimentou isso conhece esse lugar em seu corpo e sabe do que estamos falando.

Em 2008, a então estudante Maíra Gerstner concluía uma prática de pesquisa que buscava uma articulação entre a visão de mundo daqueles jovens e textos de artistas da palavra, como é o caso de Maiakóvski, Oswald de Andrade 
ou Jorge Mautner. Inspirada pela trajetória do Oficina como seria de se esperar, essa articulação não poderia se contentar com textos pretensamente "acessíveis" ou adaptáveis a eventuais fragilidades de leitura por parte dos participantes. O percurso da emissão da palavra de cada um até o jogo com textos dos autores mencionados não era o caminho da facilidade. E ele foi trilhado dentro de padrões de uma experimentação corajosa cujos rastros podem ser resgatados apenas de modo parcial e fugidio, como sempre acontece como a experiência da cena.

Hoje, alguns jovens do Bixigão seguiram pelo mundo da arte, outros se encontraram em outros caminhos. Mas o que talvez seja importante aqui pontuar é que, ao retomar os registros deste momento, podemos pensar na potência do encontro que o teatro pode trazer para a vida, seja qual for a estrada que será percorrida depois. Uma potência que não se pode mensurar e nem mesmo qualificar. Ela atravessa a singularidade de cada ser.

\section{Referências bibliográficas}

FÉRAL, J. Teatro, teoria y práctica: más allá de lás fronteras. Buenos Aires: Galerna, 2004.

FÉRAL, J. Pour une poétique de la performativité : Le théatre performatif. In: ENCONTRO MUNDIAL DAS ARTES CÊNICAS, 6., 2008, São Paulo. Anais [...]. São Paulo: Ecum, 2008.

GIMMLER NETTO, M. A. Ética, boniteza e convívio teatral entre grupos. 2010. Dissertação (Mestrado em Artes Cênicas) - Universidade Federal do Rio Grande do Sul, Porto Alegre, 2010.

PARQUE DO BIXIGA. Parque Municipal das Terras do Bixiga. São Paulo, 20 mar. 2018. Disponível em: http://bit.ly/39O2j4j. Acesso em: 4 fev. 2021.

PUPO, M. L. S. B. Entre o Mediterrâneo e o Atlântico, uma aventura teatral. São Paulo: Perspectiva, 2005.

SILVA, A. S. Oficina: do teatro ao te-ato. São Paulo: Perspectiva, 1981.

ZUMTHOR, Paul. A letra e a voz. São Paulo: Companhia das Letras, 1993. ZUMTHOR, P. Performance, recepção, leitura. São Paulo: Educ, 2000. 